\title{
Julia Klien*
}

\section{Pontifícia Universidade Católica do Rio de Janeiro}

\section{O ensaísmo de Ana Hatherly: "na fronteira entre o diálogo e o duelo com tudo”}

Resumo: Um dos aspectos medulares da poética de Ana Hatherly é o interesse na materialidade da linguagem, submetida a contínuas investigações nas mais variadas formas. Cada trabalho parece um pedaço da mesma incessante pesquisa e dá a ver uma atenção à performatividade e à fisicalidade da escrita, à busca de sua voltagem mais intranquila ou suspensiva - ensaística? Se o ensaísta, eminentemente experimental, arma um "jogo infinito" e textualiza um "pensamento tátil” (Jean-Christophe Bailly), cabe especular a configuração de um ensaísmo em muitas das experiências poéticas e visuais de Hatherly. Embora a autora também colecione textos explicitamente reflexivos, este ensaio parte da hipótese de que são observáveis na vertente dita artística da sua obra alguns de seus ensaios mais vigorosos.

Palavras-chave: Ana Hatherly, ensaio, ensaísmo, experimentação

Abstract: One of the medullary aspects of Ana Hatherly's poetics is its interest in the materiality of language, subjected to continuous investigations in the most varied forms. Each work seems to be a piece of the same incessant research and shows an attention to the performativity and physicality of writing, to the search for its most uneasy or suspensive - essayistic? - voltage. If the essayist, eminently experimental, sets up an "infinite game" and textualizes a "tactile tought" (Jean-Christophe Bailly), it is worth speculating on the configuration of an essayism in many of Hatherly's poetic and visual experiences. Although the author also collects explicitly reflective texts, this essay starts from the hypothesis.

Keywords: Ana Hatherly, essay, essayism, experimentation

1.

Um perfil. Ou, melhor, uma linha contínua feita a caneta, traço grosso, só o contorno lateral de um rosto. Ou trecho de rosto: nariz, boca, queixo; a boca está bem aberta, mas não excreta nada. Alguns garranchos não recheiam por completo o perímetro desse rosto que ocupa talvez um terço (o direito) de um quadrado. Essa escrita ilegível está no 
perfil, represada, circunda-o internamente, e nada dela fura o traço espesso que marca a fronteira entre dentro e fora do contorno do rosto. Em outra página, o mesmo contorno do mesmo jeito, a boca bem aberta. Desta vez, o rosto está integralmente preenchido por tinta preta e contrasta com o branco do restante do quadrado. A escrita agora se lê: o alfabeto despejado como numa sopa. As letras, tipografadas, são discerníveis, mas descontínuas. Algumas maiúsculas, outras minúsculas, de tamanhos variados, todas expelidas pela boca muito aberta, tanto mais profusas e emboladas quanto mais dentro dela. Outra página: não há rosto - só letras, ponto de interrogação, traço, seta e chave; lê-se, como que em três degraus descendentes, "RU?", "mNåå” e "So". Outras também contêm letras, sinais gráficos, quase-palavras e mais letras. E ainda outra: letras, muitas, em aparente queda vertiginosa. Aqui e ali, pontos, linhas, variações do rosto e esporádicos algarismos.

O traço agora é finíssimo, a nanquim. O ângulo do rosto mudou um pouco, pois o contorno inclui a testa. A escrita mais uma vez ilegível - cursiva, contínua, sem palavra e nem pausa - alterna-se entre a artesania meticulosa e uma espécie de surto sígnico. $\mathrm{E}$ parece devorar o rosto ao passo do seu êxodo, como o trânsito de vermes por um crânio. É indecidível o movimento da caligrafia, entre invadir e escorrer. ${ }^{2}$

\section{2.}

O que se encontra em cada uma das páginas de O Escritor é da ordem do que a sua autora, Ana Hatherly, nomeia "texto-não-texto" (Hatherly 1979a). Esse termo designa experiências que miram a erosão da discursividade e, mais, não cedem pacificamente nem mesmo à categoria estabelecida dos poemas visuais. São investigações gráficas, tipográficas, caligráficas, disruptivas de sintaxe e sentido, que confluem com o entendimento de Hatherly sobre a "poesia como pintura de signos" e como "aventura física e mental" (Costa 2007: 19). Os textos-não-textos, conforme se movimentam, suspendem as classificações que, ao codificá-los, poderiam obstruir sua vocação experimental: plasmam uma textualidade refratária à coagulação da textualidade.

Convém olhar o termo mais de perto: o não vibra no centro e afirma, de fato, a recusa de uma textualidade conformada; note-se, no entanto, a duplicação do texto, que emoldura essa recusa. A poética hatherliana é mesmo movida pelo constante impulso de transtorno ou desestruturação de estabilizadores morfológicos, sintáticos e semânticos mas o seu motor hospeda sempre uma perseguição da escrita, de suas possibilidades, isto é, uma multiplicação dos modos de esgarçar seus limites.

Quanto ao traço, interessa a sua volubilidade. Em O Escritor, a variação da espessura das linhas é um dos moduladores da porosidade entre desenho e escrita. Se, numa página, uma linha grossa e firme separa um rosto de um texto-não-texto, noutra, a tenuidade do traço constitui um importante fator de perturbação entre os domínios visual e textual: a linha é quase rosto e quase escrita, ou rosto-escrita, num fluxo indecomponível. Essas variações de espessura soam como uma espécie de metonímia da obra de Hatherly - que, 
em seu conjunto, se assemelha a uma imensa escala de gradações térmicas do mesmo (pluriforme) ato: deformar a escrita, ou esfoliá-la.

Do experimentalismo dos anos 1960 ao "neograffiti” dos anos 2000, Ana Hatherly perseguiu uma escrita orientada pelo anseio de vivificação da palavra, de uma palavra-fluxo que involuísse a uma intensa materialidade. Nessa direção, compôs uma obra que só poderia ser definida, aproximativamente, como um teste incansável da elasticidade das fronteiras entre palavra e imagem; uma obra que parece ter sido toda disparada pelo ímpeto de borrar - ou ao menos estremecer - esses limites.

Em Mapas da Imaginação e da Memória, por exemplo, vê-se uma série de grafismos esvaziados de sentido e desvinculados de uma língua, cuja aparência às vezes evoca letras; às vezes, ideogramas. São apenas desenhos? Quase: Joana Batel observa que "[o]s traços negros há muito perderam seu rosto de escrita, mas conservam ainda [...] a máscara da palavra" (Batel 2014: 297). ${ }^{3}$

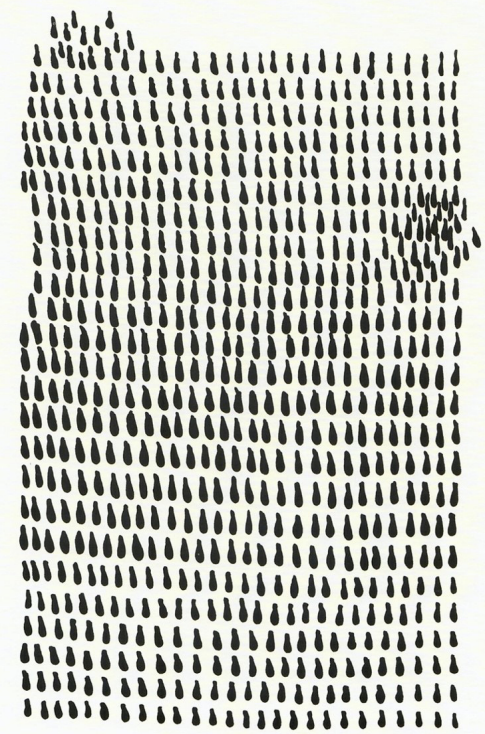

Fig. 1: Ana Hatherly, trabalho de Mapas da Imaginação e da Memória, 1973

Batel aponta uma "indecisão entre a escrita e o desenho", um "entre (do desenho e da escrita) abissal, vertiginoso" (idem: 299). A ideia de indecisão soa mais exata do que as noções de hibridismo ou trânsito, atribuíveis ao trabalho de Hatherly. A poética hatherliana é mesmo agudamente móbil, mas é como se esse deslocamento fosse desterritorializado: a estabilidade dos domínios que se quer perturbar não está pressuposta ou consentida; portanto, não há tráfego seguro, nem interseção pacificadora; no máximo, um entre-abismo, um entre-vertigem. 
Seja nos grafismos mais a-significantes, seja nos poemas mais estruturados, a poética de Ana Hatherly parece de fato habitar e dilatar um entre cada vez mais convulsivo, forçando a escrita a uma experimentação contínua da performatividade; a linguagem, aqui, como o corpo, não é senão "pensamento-acto" (Hatherly 2017: 202). E lembremos: "[o]s textos serão cada vez mais textos-actos. Ao texto-acto corresponde o poeta-actor, porque a obra será cada vez mais acção [...]" (Hatherly 2001: 388).

Nesse sentido, as experiências textuais de Hatherly guardam afinidade com o que Georges Bataille entende por informe, não entregando mais sentidos, e sim tarefas. ${ }^{4}$ É mesmo detectável, tanto na vertente efetivamente assêmica da escrita de Hatherly quanto nos outros muitos momentos em que "o sentido/ permanece/ indecidível" (idem: 304), uma "potência performativa" - como a de que fala Marcelo Jacques de Moraes em torno do informe batailliano:

Se a suposição do sentido das palavras remete em geral à possibilidade de sua permutabilidade, de sua transmissão, de sua fixação a "coisas" e de sua consequente ereção em figura, Bataille, ao privilegiar aqui a dimensão da tarefa das palavras, em oposição ao sentido, considera-as em sua relação com que ainda não está dado, com sua potência performativa sobre as formas informes que elas postulam [...]. (Moraes 2018: 87)

É, portanto, sob a vertigem de um entre que se impõem as tarefas das palavras de Hatherly. Um entre que se evidencia na indiscernibilidade entre palavra e imagem, escrita e desenho? Sim, essas desordens gráficas reiteradamente arrastam a linguagem para um feixe de involuções: seja por decomposições, derrames, explosões ou gagueiras, a frase se desmantela a caminho da palavra; a palavra, da letra; a letra, do traço. Mas mesmo essa porosidade fica cada vez menos perscrutável, e a interação entre os grafemas escapa a qualquer organização para tornar-se como que erótica. Conflagra-se um transtorno sísmico, imprecisável, cujos impactos podem ser sentidos - e resistem à delimitação.

Fig. 2: Ana Hatherly, “Carta cheia de esperança”, A Reinvenção da Leitura, 1975 
Sob a vertigem de um entre, então. Só um?

3.

Em Sobre o fio, Georges Didi-Huberman elabora um elogio do inacabado, da "obra sempre em obras", em contraposição à imobilidade constitutiva da noção corrente de obra-prima (Didi-Huberman 2019: 8). Didi-Huberman pondera que, desde Duchamp, deparamo-nos com um tipo de obra "concebida como um perpétuo ensaio: portanto, jamais fechada de direito, sempre por refazer" (ibidem). E continua:

O que equivaleria dizer: nossas obras não têm rabo nem cabeça. Difíceis por isso de enquadrar: elas não estão fechadas nos limites de um começo (a cabeça) e de um fim (o rabo). Elas não se submetem às hierarquias do alto (a cabeça) e do baixo (o rabo). Que não tenham rabo nem cabeça quer dizer que não têm fim, que são inesgotáveis e nunca param de relançar suas próprias hipóteses. [...] Que não tenham nem rabo nem cabeça quer dizer ainda que se movem em todos os sentidos, em expansão, em extensão [...]. Isso quer dizer que elas se situam fora de qualquer sentido orientado (a cabeça na frente, o rabo atrás) [...]. (idem: 8-9)

O temperamento das obras sem rabo nem cabeça é aquele da tentativa, da experimentação. Nesse regime, não lhe bastando a "força da arte", o artista também precisa da "fraqueza de luminosidades pacientemente elaboradas no espaço da pesquisa ou do ensaio, essa forma do pensamento capaz, justamente, de pôr em relação territórios disciplinares heterogêneos" (idem: 21 ); ${ }^{5}$ e cria um percurso infinitamente relançado, extensível - um percurso-corpo, nem cabeça nem rabo, que se estica e quase engole a obra. ${ }^{6}$

A mobilidade dessas "obras sempre em obras" embosca tanto a fixidez quanto o valor, atributos da obra-prima, promovendo "um deslocamento perpétuo, modesto e obstinado, do valor em geral", nas palavras de Didi-Huberman (idem: 11). E aqui interessa menos o que e mais como desloca.

4.

É o caso de avançar um pouco na questão do deslocamento e no seu parentesco com algumas estratégias de ilegibilidade. Mais do que uma recusa veemente do legível, Ana Hatherly parece acender "um deslocamento perpétuo, modesto e obstinado" do que foi conformado como tal. Maria Filomena Molder sugere que Hatherly, "como em certas curas arcaicas, acicatou as palavras e as suas letras a morderem-se a si próprias, perseguindo-as como um amante laboratorial" (Hatherly 2017: 67). E observa, em muitos desenhos, a mobilidade das "palavras minúsculas enlaçadas, emaranhadas, sobrepostas, ágeis ciclistas, trapezistas, [que] não estão ali para nós as lermos, mas para as vermos" (idem: 71). De fato, essas palavras costumam estar do lado da pressa. No entanto, também seria possível dizer que a obra de Hatherly, sobretudo em sua faceta visual, materializa uma coreografia bastante heterogênea de gradações de velocidade, densidade e legibilidade dos movimentos textuais. 
Isso quer dizer que há uma alternância entre momentos de explosões e deflações gráficas - e talvez a agilidade se entreveja justo nas passagens. A palavra aparece ora como "vertigem de espuma" (Hatherly 2005: 93), ora "como tumor que arrebenta" (idem: 95), e a escrita "é o prolongamento extensíssimo da mão" e "onda surda" (idem: 59), mas todos os modos de deformá-las tornam mais elástica e difusa a acepção usual de legibilidade. Entre o despejo caudaloso e a subtração radical, explora-se e se alarga a ideia de leitura à base de choques térmicos. $\mathrm{E}$, na mesma medida em que se alternam os volumes das textualidades, entre vapores de letras e metástases de tintas, também parece acontecer algo como a coalescência do que é e do que não é legível, produzindo uma outra legibilidade.

Nuno Ramos, no ensaio de abertura de seu último livro, Verifique se o mesmo, situa, ao mesmo tempo, João Gilberto, Lygia Clark, Graciliano Ramos e Mira Schendel "no palácio de Moebius". " "[U]m movimento em suspenso, indeciso entre ir e vir" (Ramos 2019: 24), marcaria essas poéticas - pertencentes, cada uma a seu modo, a um paradigma artístico cumpridor de movimentos caracterizados por impulsos para dentro e para foraem bombeamentos cíclicos. Em Schendel, especificamente, Ramos sublinha a alternância entre um movimento de expansão dos signos e outro, "de contenção, de resguardo" (idem: 56), despertado sobretudo pela folha de papel-arroz.

As letras são quase linhas ou as linhas é que são quase letras? E será que importa tanto a diferença - não estão nascendo os alfabetos, rasuras, caligrafias, em várias línguas ou quase línguas [...], como extensores da mão, dedos, unhas com que Mira produzia suas monotipias, de modo a nos dar a certeza de que podemos ler todas elas? Não estão entranhados o alfabeto e a escrita em seus desenhos como os próprios traços nas folhas de papel-arroz, sugerindo uma espécie de alfabetização maluca, espalhada fisicamente por tudo? Para Mira Schendel, o corpo que desenha emite naturalmente signos, numa visão discreta, mas ainda assim um pouco mística, de que tudo pode ser lido. (idem: 53)

A "alfabetização maluca" flagrada por Nuno Ramos no trabalho de Schendel pode ser superposta à "reinvenção da leitura" proposta por Hatherly, que experimentou um redimensionamento ininterrupto do hiato entre a leitura e a legibilidade. Sobre o processo de pesquisa para a confecção dos Mapas da Imaginação e da Memória, Hatherly diz: "constantemente estava perante textos, literalmente ilegíveis para mim - por exemplo em chinês arcaico - mas que eu, não obstante, lia" (Hatherly 1979b: 22).

O tema da leitura é mesmo um dos mais repisados por Ana Hatherly ao longo do seu trabalho; nesse sentido, o título A Reinvenção da Leitura parece servir como um dispositivo poético e, ainda, como um convite. Se, num poema, Hatherly escreve que tudo em si "são olhos vigilantes/ sem jamais pálpebra" (Hatherly 2005: 65) e, numa carta, que percorreu "toda olhos" (Hatherly 1981: 233) certa exposição, a fisicalidade da sua escrita, por seu turno, arrasta o leitor a um corpo a corpo - acendedor de uma leitura não decodificadora e intelectiva, mas também não apenas ocular. 
5.

Henri Focillon, no seu "Elogio da mão", escreve que "[a] possessão do mundo exige uma espécie de faro tátil. A visão desliza pelo universo. A mão sabe que o objeto é habitado pelo peso, que é liso ou rugoso, que não está soldado ao fundo de céu ou de terra com o qual ele parece formar um só corpo." (Focillon 2010: 11). Focillon contrapõe o aspecto receptor da face humana à ação e ao pensamento da mão. E, adiante, continua:

A mão arranca o tato à passividade receptiva, organiza-o para a experiência e para a ação. Ela ensina o homem a possuir o espaço, o peso, a densidade, o número. Criando um universo inédito, deixa sua marca em toda parte. Mede-se com a matéria que se metamorfoseia, com a forma que ela transfigura. Educadora do homem, a mão o multiplica no espaço e no tempo. (idem: 29)

Lembremos que, também para Hatherly, a mão é inteligente e o corpo é pensamento-acto. "O valor gráfico dos cabelos só é comparável ao valor táctil da sua textura" (Hatherly 2001: 162): como uma estranha e exata equação, essa frase também pode se referir aos impulsos de leitura que a poética hatherliana deflagra; para ler adequadamente os exercícios caligráficos executados pela mão inteligente, seria preciso que o leitor se tornasse todo mãos. Na realidade, o leitor ideal deveria conseguir ler com o corpo todo, confluindo com uma escrita marcadamente tátil, rítmica, nervosa, e tomando como um manual a lista de ações enumeradas em "Tacto - um sentido".

Tecer imagens com os dedos. Lembrar o mundo acumulando fios. Criar as imagens com a pele. No fundo simétrico e constante tecer a irregularidade das imagens. Quando depois de tecida se considera a imagem contra a pele do corpo sente-se a irregularidade a incerteza a descontinuidade do processo o movimento regular mais as diferenças de ritmo. Nenhum gesto é igual nenhuma sensação é igual. Hoje sinto a tua ternura amanhã a curva do teu ombro depois a dureza do teu joelho. Quero então conhecer-te como se caminhasse de noite às escuras numa sala desconhecida. Tropeçando mesmo contra os móveis e os objectos. [...] Sentir com o corpo todo. Aperceber um móvel com o ventre com as coxas sentir a permuta das texturas das temperaturas o frio assustado que percorre as costas. Um objecto que cai e se parte. Caminhar por sobre os estilhaços gritando de dor e de surpresa. (ibidem)

6.

Escreve Ana Hatherly em sua tisana 233: "O que há de impressionante na minha obra poética é o que nela há de recusa de expressão. O peso e o tamanho do que eu me recuso a exprimir eis o que eu digo-não-digo e finalmente digo" (Hatherly 2006: 100). De fato, o motor da poética de Hatherly poderia ser traduzido na conjugação entre, por um lado, uma obsessão pela escrita, e, por outro, uma aversão à expressão e ao discurso aliadas, ambas, a um insistente abalo do sentido. 
Entenda-se esse abalo como o que Roland Barthes exaltou em O Império dos Signos, ou seja, como caminho tomado na contramão das "vias de interpretação" ocidentais, "destinadas entre nós a penetrar o sentido, isto é, a fazê-lo entrar por arrombamento - e não a sacudi-lo, a fazê-lo cair, como o dente do ruminante de absurdo que deve ser o praticante do Zen, em face de seu koan" (Barthes 2016: 95). Barthes retoma o ensinamento do mestre Zen ao seu discípulo: diante de um koan (espécie de enigma do Zen-budismo), deve-se afastar tanto uma resolução (a atribuição de um sentido) quanto uma assunção de absurdidade (ainda um sentido), em proveito de uma ruminação, "até que o dente caia" (idem: 98). É este o movimento que ritma a leitura de Hatherly, e notadamente de suas estranhas tisanas: um dente que cai. E também dentes que nascem para dentro.

Era uma vez uma palavra que estava sentada à porta de casa quando passou um rato. Bela palavra diz o rato. Como ia com muita pressa deu-lhe umas dentadas e engoliu-a. Mal. A palavra ficou-lhe atravessada na garganta. Então os dentes começaram-lhe a crescer para dentro. (Hatherly 2006: 24)

Se os textos-não-textos de Hatherly erodem o discurso, esquartejam-no, as tisanas ocupam-no, à maneira de cupins, depositando-lhe uma infusão "arracional". ${ }^{9}$ A palavra está acomodada em seu lugar, a frase também, e até mesmo uma microestrutura narrativa se apresenta, mas uma plácida, espumosa demolição encontra-se ao menor toque. A tisana de Hatherly, no seu já referido parentesco com o koan budista e a tradição Zen, ${ }^{10}$ é - para ficar com Barthes - um

\footnotetext{
"despertar diante do fato", captura da coisa como acontecimento e não como substância, acesso à margem anterior da linguagem, contígua à opacidade (aliás inteiramente retrospectiva, reconstituída) da aventura (aquilo que acontece à linguagem, mais ainda do que ao sujeito). (Barthes 2016: 102)
}

Fato é que não só os trabalhos visuais mas mesmo as tisanas e grande parte dos poemas, poemas-ensaios e poemas em prosa compõem o heterogêneo programa ${ }^{11} \mathrm{de}$ vivificação da linguagem, submetida a repetidas investidas de plasticização, irritação, lubrificação. Hatherly já manifestou sua afinidade com a infância ${ }^{12}$ - os olhos renovadamente livres, espantados, o que é ratificado pelo modo como interage com os materiais, os temas e as formas que pesquisa (a exemplo da sua incursão pela técnica do grafite, que, quando dominada, parou de interessar-lhe). E talvez pudesse dizer, com Focillon, que "[o] artista prolonga os privilégios da curiosidade infantil muito além dos limites daquela idade. Ele toca, apalpa, estima o peso, mede o espaço, [...] acaricia a casca de todas as coisas e é a partir da linguagem do tato que compõe a linguagem da visão [...]" (Focillon 2010: 16). 
Cabe sublinhar: ainda que, nos termos de João Lima Pinharanda, a "inteligência performativa da mão" (Hatherly 2003: 17) de Ana Hatherly fique mais patente nos experimentos visuais, ela também trabalha, de modo talvez magmático, no que poderia ser considerado estritamente literário ou poético. Os versos ou a sintaxe não imobilizam o ímpeto tátil e performativo das palavras; e nem mesmo o nome próprio, supostamente acostumado, escapa ao revolvimento, à investigação mais material:

Abre-se a grande porta:

$$
\text { A N A ! }
$$

Salto no ar

salto no ar absoluto precedida do meu nome

seguida do meu nome

O meu nome atira-me para a frente

empurra-me para a frente

corre pelo ar absoluto

eu caio no fundo

Olho para o alto: o nome é um triângulo de basalto

Fecho os olhos.

Penso na existência do nome.

Quero chorar. Doem-me os olhos. Choro lágrimas de tinta.

Quero olhar dizer o nome. A minha boca está cheia de tinta.

Estou dobrada. Quero erguer-me.

Estou dentro.

$$
\begin{aligned}
& \begin{array}{l}
\text { Tudo que eu sou escreve o nome } \\
\text { é para escrever o nome } \\
\text { o vómito do nome } \\
\text { a agonia do nome }
\end{array} \\
& \text { A minha pele é o chumbo líquido do nome }
\end{aligned}
$$

Os meus membros são as teclas da máquina de escrever o nome

\section{ANA ANA ANA ANA ANA ANA ANA ANA ANA ANA ANA ANA}

(Hatherly 2001: 154)

Mais do que estranhar o nome, ANA parece se "desbatizar"13 fisicamente, é possuída e obstruída pelo nome. O nome vira represa e enguia, tumor que arrebenta, enxame de letras, enxame de bigornas, a boca cheia de tinta lembra uma boca cheia de larvas, tudo é uma língua tentando um nome, um olho tentando um nome, um vômito tentando, uma lágrima tentando, o nome esmaga e tudo é nome, rompe a barragem e tudo é pele, tecla, tinta, carne, nome. 
7.

O que Ana Hatherly busca palpabilizar, na superfície mais imediata da escrita, são os sismos de uma "palavra-corpo", para ficar com Sandra Guerreiro Dias (2017: 5). Sua poética constitui, então, nada menos do que um amontoado de "palavras-corpo" - que constituem, por sua vez, "obras sem rabo nem cabeça"? Se, por exemplo, os Mapas da Imaginação e da Memória, A Reinvenção da Leitura e as centenas de tisanas se assemeIham, individualmente, ao feitio dessas obras sem rabo nem cabeça e sempre em obras, a soma total compõe uma enorme obra extática, movediça, também ela sem cabeça nem rabo, corpo imenso se estendendo, monstruoso, feito de incontáveis palavras-corpo e sucessivas texturas.

Dito de outro modo: as obras de Hatherly compõem um aglomerado de formas informes que mal suportam suas tarefas e dão a ver uma singular "voragem investigativa", nos termos de Floriano Martins (apud Hatherly 2005: 14). São espasmos de pensamento, tanto pela rapidez como pela corporalidade. Não raro, um trabalho, em sua versão final, mais parece um esboço, pedaço de pesquisa, matéria vulnerável a eternos desvios; turbilhona ao mesmo tempo mais de um entre - infiltrando-se entre o desenho e a escrita, entre o percurso e o resultado, entre a legibilidade e a ilegibilidade: "[v]ivo na fronteira entre o diálogo e o duelo com tudo" (idem: 124).

O certo é que, a cada vez, mais importa o próprio ato de ferver a linguagem, promover e tatear sua ebulição, do que almejar o estado resultante desse processo. Assim, cada trabalho se apresenta como um trecho de uma excursão interminável pelas engrenagens da escrita - mas estas não estão sob a proteção de um dentro: mostram-se, fratura exposta ou carne viva. Tampouco funcionam: operam com a condição de seu próprio curto-circuito, superaquecidas, beirando o tilt. Já disse Hatherly, muito a propósito, que o poeta "[é] uma máquina eta-erótica em que as discrepâncias/ são a fulgurância da máquina" (Hatherly 2001: 61).

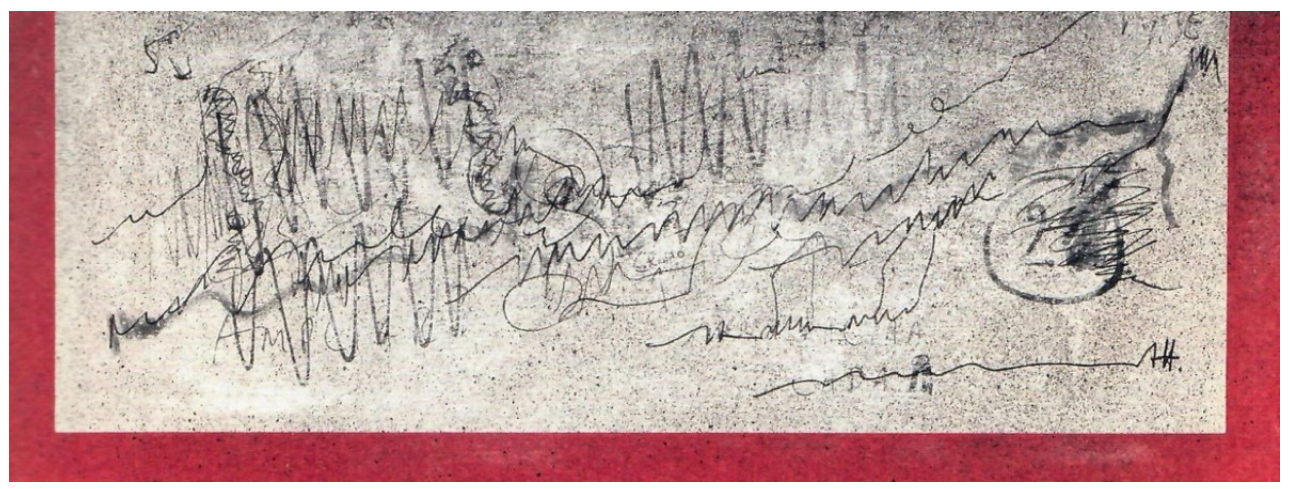

Fig. 7: desenho de Ana Hatherly (n.d.) 
As obras de Ana Hatherly não se movem segundo um desejo de Obra: exalam, antes, as dimensões do jogo, do acaso, do exercício (em sua dupla acepção); ${ }^{14}$ e, se seguem algum caminho, é aquele tão físico quanto inconclusivo, percorrível apenas sob o signo de um "pensamento tátil”, de que falou Jean-Christophe Bailly (2017: 14). Em sua agilidade e sua volatilidade, no modo como exorbita seus trajetos, o trabalho de Hatherly expõe sua disposição ensaística: menos deambulação do que vazamento, como o ensaio, "é extensível porque se estende, porque se verte. Vertendo-se assim, ele se ilimita, transbordando sobre os outros gêneros e transbordando também de si mesmo. Às vezes sabe para onde vai; outras vezes se perde no caminho" (idem: 22).

Há mesmo algo como uma pulsão ensaística embrenhada no próprio tecido da poética hatherliana. Não se trata de imobilizar essas diversas experimentações na constrição de um gênero, exigindo-lhes um contorcionismo indesejável, mas, bem ao contrário, perceber a "forma particularmente nervosa de intranquilidade" (idem: 11) que lhes concerne. Forma essa que - como diz Bailly - se move aos saltos, aos ricochetes: de tisana em tisana e de pedra em pedra, ${ }^{15}$ de mapa em mapa e de letra em letra, alarga o percurso toda vez que pousa, e, escorregando sempre, nunca para de pular, nem de cair.

\section{NOTAS}

* Julia Klien é doutoranda no Programa de Pós-Graduação em Literatura, Cultura e Contemporaneidade da Pontifícia Universidade Católica do Rio de Janeiro (PPGLCC/PUC-Rio) e bolsista CAPES. Dedica-se à pesquisa nas áreas de Letras e Artes, com interesse especial em experiências de tensionamento e perturbação dos domínios artístico e teórico, verbal e visual.

${ }^{1}$ O presente trabalho foi realizado com o apoio da Coordenação de Aperfeiçoamento de Pessoal de Nível Superior - Brasil (CAPES) - Código de financiamento 001.

${ }^{2}$ Descrevo, fora da sequência, algumas das páginas de O Escritor (1975), disponível integralmente no Arquivo Digital da Poesia Experimental Portuguesa: <https://po-ex.net/taxonomia/materialidades/planograficas/anahatherly-o-escritor/>. Para um estudo detido do livro, ver Teixeira 2009.

3 Batel alude aqui ao poema "A máscara da palavra", de que cito uma estrofe: "Paraíso acidental/ metódico exercício/ a máscara da palavra/ colou-se-nos ao rosto:/ agora é/ o nosso mais vital artifício." (Hatherly 2005: 63). ${ }^{4}$ Ver o verbete "Informe" da revista Documents (Bataille 2018).

${ }^{5}$ Nesse trecho, Didi-Huberman se refere ao trabalho de Pascal Convert. 
${ }^{6}$ A propósito de engolir, a ensaísta Christy Wampole lembra que "[e]m italiano, a palavra para ensaio é saggio e tem a mesma raiz do termo assaggiare, que significa provar, experimentar ou beliscar comida" (Wampole 2018: 246).

${ }^{7}$ Ver Ramos 2019. É o caso de frisar o atributo central do anel de Moebius: ele se constitui como um "objeto não orientável", segundo os termos da matemática, pois é impossível delimitar-lhe um verso e um anverso, um dentro e um fora, e percorrê-lo, portanto, seria traçar um caminho infinito.

${ }^{8} \mathrm{O}$ livro que reúne os trabalhos visuais de Hatherly tem por título $A$ Mão Inteligente - expressão que deriva de uma observação de AH ao processo dos Mapas da Imaginação e da Memória (1973), livro em cujo prefácio descreve a experiência de ver a sua "mão tornar-se inteligente".

${ }^{9}$ Retomo o termo usado por Mira Schendel na descrição do seu trabalho exposto na 10o Bienal de São Paulo, 1969. Como Hatherly, Schendel também se interessou pelo Zen. Cito o trecho: “ $A$ 'visibilidade' do invisível. O 'silêncio visual'. Esta experiência tende ao arracional, além do irracional e do racional." (Schendel apud Dias 2003: 126).

${ }^{10}$ Diz Hatherly (2006: 14): "[...] aí pode detectar-se algo herdado da tradição Zen: todas as Tisanas obedecem a um princípio semelhante ao do koan budista, são sempre, directa ou indirectamente, um acontecimento [...]. Em todas as Tisanas encontra-se algo dessa 'indeterminação deslizante' do pensamento Zen [...]." A respeito da relação entre aspectos da tradição oriental e as Tisanas de AH, ver Almeida 2013 e Gastão 2017.

${ }^{11}$ Provavelmente por seu parentesco com a performance, Ana Hatherly era muito afeita à noção de programa convocada aqui como alternativa à ideia menos interessante de projeto.

${ }^{12}$ Ver a entrevista concedida por Ana Hatherly a Ana Marques Gastão, “Palavras que riem” (Hatherly 2005).

${ }^{13}$ Remonto à expressão de Jean-Christophe Bailly, evocada por Marcelo Jacques de Moraes em ensaio sobre o autor (Moraes 2017).

${ }^{14}$ Além da dimensão mais imediata - e já insinuada - do teste, remeto também a um trecho das "considerações necessárias" ao livro Anagramático, de 1970, publicadas na antologia Um calculador de improbabilidades: "Sei que estou empenhada numa espécie de corrida de obstáculos mas sei também que ser autor é uma forma de ser atleta; e que nunca se consegue ir longe demais; diante de nós está o infinito, o infinito das possibilidades: o improvável” (Hatherly 2001: 377).

${ }^{15}$ Diz a tisana 149: "Saltamos de palavra em palavra como quem salta de pedra em pedra ao cruzar um ribeiro. Em todo esse processo o que se pretende: não ser arrastado pela corrente ou evitar a contaminação do percurso? e a contaminação da pedra?" (Hatherly 2006: 75.) 


\section{BIBLIOGRAFIA}

Almeida, Catarina Nunes de (2013), “Ana Hatherly e a lição oriental”, Revista Desassossego, no 10, <https://www.revistas.usp.br/desassossego/article/view/59520/73191> (último acesso em 28/03/2021).

Bailly, Jean-Christophe (2017), O Ensaio e a Anedota, Rio de Janeiro, Zazie Edições, <https:// static1.squarespace.com/static/565de1f1e4b00ddf86b0c66c/t/5a5e071753450a b8996b7123/1516111643821/ZAZIE+EDICOES_PEQUENA+BIBLIOTECA+DE+ENSAIOS_ JEAN+CHRISTOPHE+BAILLY_2017_2.pdf> (último acesso em 28/03/2021).

Bataille, Georges (2018), "Informe”, in Documents, Florianópolis, Cultura e Barbárie: 147. Batel, Joana (2014), "O rosto da linha - Ana Hatherly”, Diacrítica, v. 18, no 3: 289-307.

Costa, Horácio (2007), "Entrevista com Ana Hatherly”, Via Atlântica, no 11, 9-22, <http://www.revistas.usp.br/viaatlantica/article/view/50659> (último acesso em 28/03/2021).

Dias, Geraldo Souza (2003), "Contundência e delicadeza na obra de Mira Schendel”, ARS, v. 1, no 1: 117-138, <https://www.scielo.br/scielo.php?pid=S167853202003000100010\&script=sci_arttext> (último acesso em 28/03/2021).

Dias, Sandra Guerreiro (2017), "Poesia e corpo, em Ana Hatherly”, Plural Pluriel, no 16, <https://www.pluralpluriel.org/index.php/revue/article/view/87> (acesso em 28/03/2021).

Didi-Huberman, Georges (2019), Sobre o fio, Florianópolis, Cultura e Barbárie.

Focillon, Henri (2010), “Elogio da mão”, Serrote, Instituto Moreira Salles, no 6: 7-29.

Gastão, Ana Marques (2017), "As 'Tisanas' de Ana Hatherly - auto-retrato de um samurai ocidental”, Plural Pluriel, no 16, <https://www.pluralpluriel.org/index.php/revue/ article/view/83> (último acesso em 28/03/2021).

Hatherly, Ana (1979a), "O texto-não-texto: a propósito de O Escritor”, in O Espaço Crítico. Do simbolismo à vanguarda, Lisboa, Editorial Caminho, 107-112.

-- (1979b), A Reinvenção da Leitura, Lisboa, Editorial Futura, <https://po-ex. net/?s=a+reinvenção+da+leitura> (último acesso em 28/03/2021).

-- (1981), "A arte de deixar as coisas acontecerem: uma carta de Ana Hatherly a Sylvester Houéddard", in PO-EX: Textos Teóricos e Documentos da Poesia Experimental Portuguesa, Lisboa, Moraes Editores, 1981, 233-234.

-- (2001), Um Calculador de Improbabilidades, Lisboa, Quimera.

-- (2003), A Mão Inteligente, Lisboa, Quimera.

-- (2005), A Idade da Escrita e Outros Poemas, São Paulo, Escrituras Editora.

-- (2006), 463 Tisanas, Lisboa, Quimera.

-- (2017), Território Anagramático, Lisboa, Documenta.

Moraes, Marcelo Jacques de (2017), “Jean-Christophe Bailly e a legenda(gem) dispersa do mundo: comparições, ricochetes, desarraigamentos”, Aletria, v. 27, no 3: $97-$ 111, <http://www.periodicos.letras.ufmg.br/index.php/aletria/article/view/12428> (último acesso em 28/03/2021). 
-- (2017), Sobre a Forma, o Poema e a Tradução: a Incerteza das Formas, o Fracasso do Poema, Língua contra Língua, Rio de Janeiro, 7 Letras.

Ramos, Nuno (2019), Verifique se o mesmo, São Paulo, Todavia.

Teixeira, Claudio Alexandre de Barros (2009), "O Escritor: uma 'máquina de produzir desordem'”, Revista Poiésis, no 14, 61-67, <https://periodicos.uff.br/poiesis/article/ view/27068> (último acesso em 28/03/2021).

Wampole, Christy (2018), "A ensaificação de tudo", in Doze ensaios sobre o ensaio, São Paulo, Instituto Moreira Salles, 242-249. 